\title{
Tyrosinase Inhibitory Activity, 3D QSAR, and Molecular Docking Study of 2,5-Disubstituted-1,3,4-Oxadiazoles
}

\author{
Ramesh L. Sawant, Prashant D. Lanke, and Jyoti B. Wadekar \\ Department of Pharmaceutical Chemistry and PG Studies, College of Pharmacy Padmashri Dr. Vithalrao Vikhe Patil Foundation, \\ PO MIDC, Vilad Ghat, Ahmednagar 414111, India
}

Correspondence should be addressed to Ramesh L. Sawant; sawantrl@yahoo.com

Received 19 January 2012; Revised 15 May 2012; Accepted 20 May 2012

Academic Editor: Romdhane Karoui

Copyright (C) 2013 Ramesh L. Sawant et al. This is an open access article distributed under the Creative Commons Attribution License, which permits unrestricted use, distribution, and reproduction in any medium, provided the original work is properly cited.

\begin{abstract}
In continuation with our research program, in search of potent enzyme tyrosinase inhibitor, a series of synthesized 2,5-disubstituted 1,3,4-oxadiazoles have been evaluated for enzyme tyrosinase inhibitory activity. Subsequently, 3D QSAR and docking studies were performed to find optimum structural requirements for potent enzyme tyrosinase inhibitor from this series. The synthesized 20 compounds of 2,5-disubstituted-1,3,4-oxadiazole series were screened for mushroom tyrosinase inhibitory activity at various concentrations by enzyme inhibition assay. The percentage enzyme inhibition was calculated by recording absorbance at 492 $\mathrm{nm}$ with microplate reader. 3D QSAR and docking studies were performed using VLife MDS 3.5 software. In the series 2,5disubstituted-1,3,4-oxadiazoles enzyme tyrosinase inhibitory activity was found to be dose dependent with maximum activity for compounds $\mathbf{4 c}, \mathbf{4 h}, \mathbf{4 m}$, and $\mathbf{4 r}$. 3D QSAR and docking studies revealed that more electropositive and less bulky substituents if placed on 1,3,4-oxadiazole nucleus may result in better tyrosinase inhibitory activity in the series.
\end{abstract}

\section{Introduction}

Tyrosinase (E.C. 1.14.18.1), known as polyphenol oxidase (PPO), is a multifunctional, glycosylated, and coppercontaining enzyme from the oxidase superfamily widely distributed in microorganisms, plants, and animals [1]. It is a nonessential amino acid made by the body that is a building block for several important neurotransmitters like epinephrine, norepinephrine, serotonin, and dopamine. It plays a key role in melanin biosynthesis catalyzing two divergent reactions: the hydroxylation of monophenols (cresolase or monophenolase activity) and the oxidation of $o$-diphenols (catecholase or diphenolase activity) into reactive $o$-quinones [2-4]. It is involved in human neuromelanin formation in the substantia nigra of the brain and dopamine neurotoxicity and contributes to Parkinson's disease-related neurodegeneration. In insects, tyrosinase is uniquely associated with different physiologically important biochemical processes, including sclerotization of the insect cuticle, defensive encapsulation and melanization of foreign organisms, and wound healing [5-10].
Tyrosinase inhibitors have become increasingly important in the field of medicine, agriculture, and cosmetics [11]. Presently, tyrosinase inhibitors have been a great concern due to its role in both mammalian melanogenesis and fruit or fungi enzymatic browning. Although melanin has photoprotective function in human skin, the accumulation of an abnormal amount of melanin in different specific parts of the skin resulting in more pigmented patches (melasma, freckles, ephelides, senile lentigines, etc.) might become an esthetic problem $[12,13]$. In addition, enzymatic browning in fruit and fungi is undesirable, for example, fresh fruits, beverages, vegetables, and mushrooms which decrease the commercial value of the products [14]. These phenomena prompted us to design novel tyrosinase inhibitors with higher bioactivities that could be useful in skin whitening and antibrowning of foods.

In continuation with our earlier work, here we report enzyme tyrosinase inhibitory activity, three-dimensional quantitative structure activity relationship (3D QSAR) analysis, and molecular docking study with enzyme tyrosinase of 
series of 2,5-disubstituted-1,3,4-oxadiazoles synthesized and reported by us [15].

\section{Materials and Methods}

2.1. Tyrosinase Inhibitory Activity. As an extension of our work, synthesized 20 analogues of 2,5-disubstituted-1,3,4oxadiazole series (Table 1) were used to study their enzyme tyrosinase inhibitory activity. Tyrosinase inhibition activity was determined by the method described earlier [16]. The title compounds were dissolved in DMSO. The 96 well plate was prepared by applying $140 \mu \mathrm{L}$ of phosphate buffer ( $\mathrm{pH}$ 6.8), $20 \mu \mathrm{L}$ of mushroom tyrosinase (48 units $/ \mathrm{mL}$ ), $20 \mu \mathrm{L}$ of sample, and $20 \mu \mathrm{L}$ of DL-DOPA $(0.85 \mathrm{mM})$ to make the concentrations of $10,20,40,80$, and $100 \mu \mathrm{g} / \mathrm{mL}$. After incubation for 10 minutes, the enzyme activity was determined by measuring the absorbance at $492 \mathrm{~nm}$ using the microplate reader (Biotek Company, US). Kojic acid $(1 \mathrm{mg} / \mathrm{mL}$ ) was used as positive control. The percentage of tyrosinase inhibition was calculated as follows:

$$
\% \text { Inhibition }=\frac{A-B}{A} \times 100,
$$

where, $A$ and $B$ are absorbance at $492 \mathrm{~nm}$ with and without test sample, respectively. The percentage tyrosinase inhibition at various concentrations of title compounds was calculated (Table 2), and logarithmic value of percentage inhibition at $100 \mu \mathrm{g}\left(\log \% I_{100 \mu \mathrm{g}}\right)$ was used as a dependant variable for the development of valid 3D-QSAR models.

\subsection{Computational Details}

2.2.1. Geometry Optimization. The 3D QSAR studies of 2,5-disubstituted-1,3,4-oxadiazole derivatives were carried out using VLife molecular design suite software version 3.5 (MDS 3.5) running on Pentium IV processor. Threedimensional structures of title compounds were constructed and optimized their geometries to make the conformations with least potential energy using merck molecular force field (MMFF) and MMFF charge for the atom [17] followed by considering distance-dependent dielectric constant of 1.0 and convergence criteria (rms gradient) of $0.01 \mathrm{kcal} / \mathrm{mol}$.

2.2.2. Alignment of Molecules. All molecules in the data set are aligned by template-based method where a template is built by considering common substructures in the series (Figure 1). Highly bioactive energetically stable conformation in the series is chosen as a reference molecule (Figure 2) on which other molecules are aligned (Figure 3 ).

2.2.3. Activity Prediction. The predictability of the QSAR model would be good if the values of biological activity predicted by the QSAR model do not appreciably differ from the observed results of biological activity for the given data set. Quality of selected models was further ascertained by $r^{2}, q^{2}$, and $F$ test. The models were cross-validated by "leave one out" scheme and cross-validation corelation coefficient
TABLE 1: Structures of 2, 5-disubstituted-1,3,4-oxadiazoles.

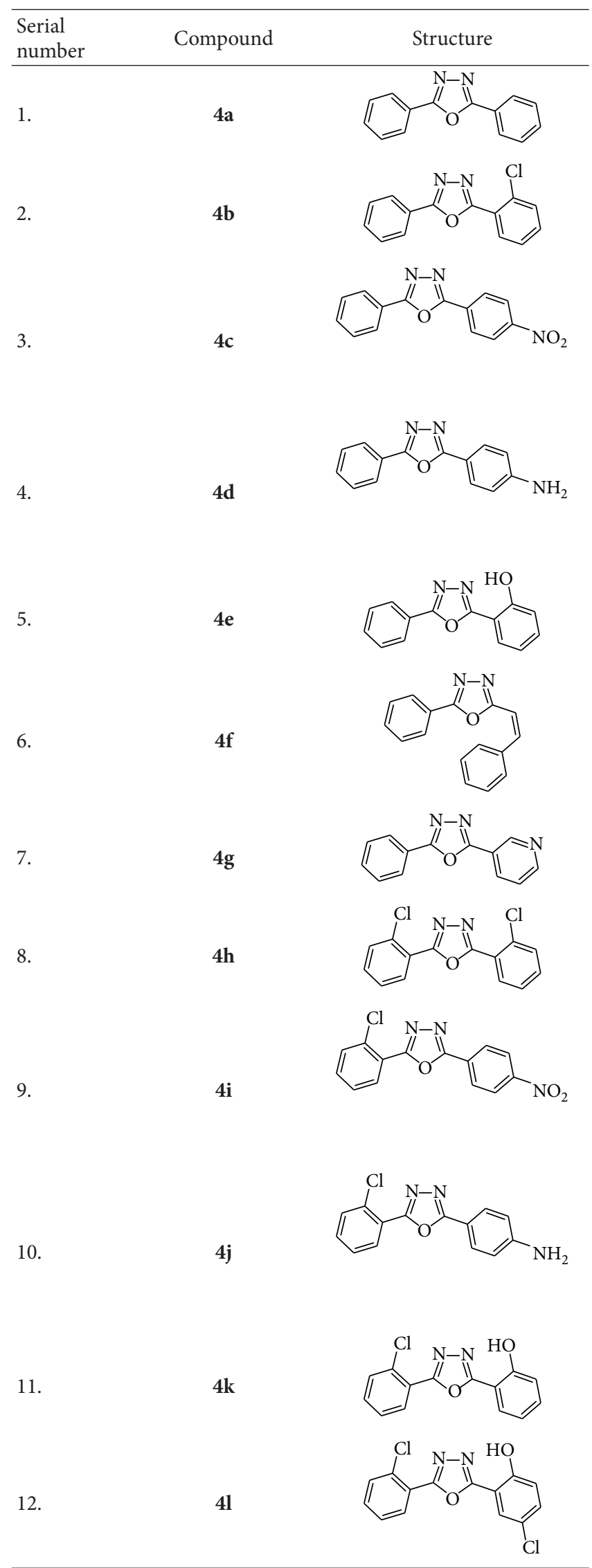


TABLe 1: Continued.

Serial 2 compound

$q^{2}$ was calculated. The model with high $q^{2}$ value is said to have high predictability.

2.2.4. $3 D$ QSAR. Several $3 \mathrm{D}$ QSAR techniques such as comparative molecular field analysis (COMFA), comparative molecular similarity analysis (COMSIA), and $k$-nearest neighbor $(k \mathrm{NN})$ [18] are being used in modern QSAR research. In the present study, molecular field analysis coupled with partial least squares (PLS) was applied to obtain a 3D QSAR model [19]. The calculated steric and electrostatic field descriptors were used as independent variables and log $\% I_{100 \mu \mathrm{g}}$ values were used as dependent variables to derive the 3D QSAR models.

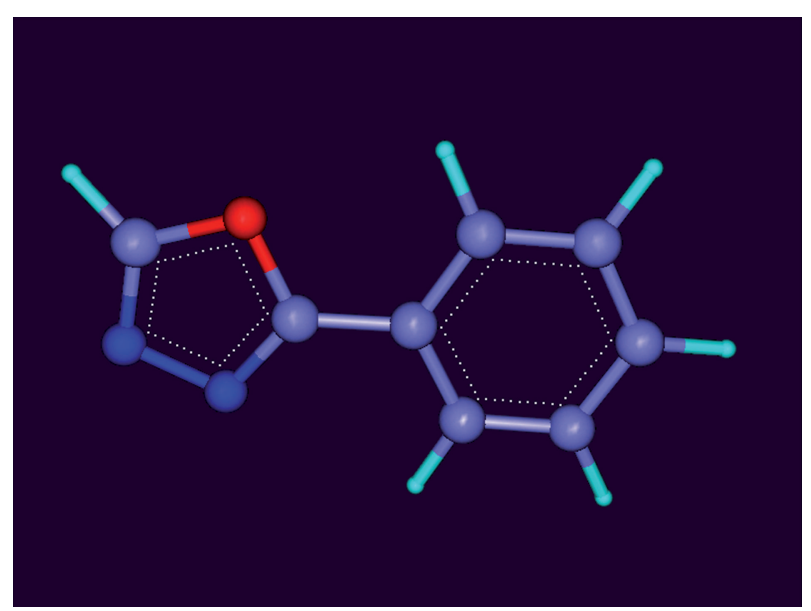

FigURE 1: Template (ball and stick).

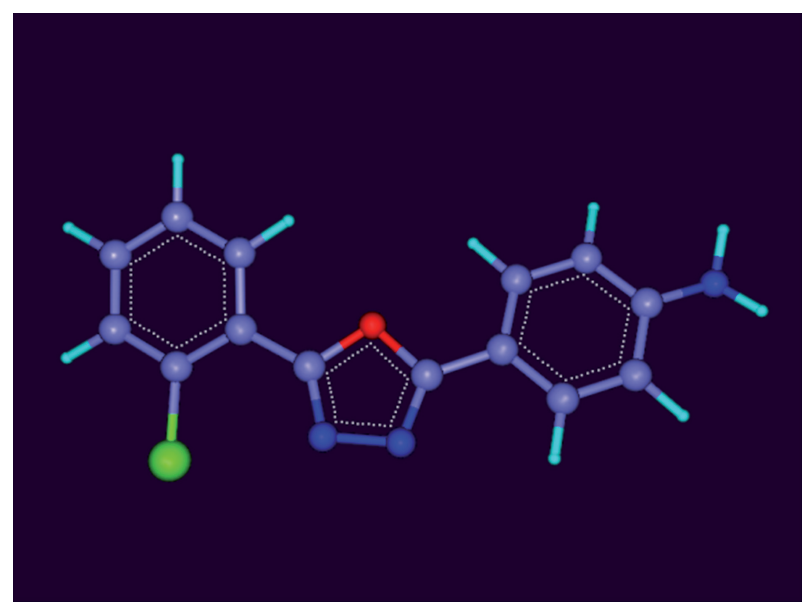

FIGURE 2: Reference molecule (compound 4j).

2.2.5. Docking. The crystal structure of mushroom tyrosinase (1wx2) was obtained from protein data bank and water molecules in the crystal structure were deleted. The optimized receptor was then saved as mol file and used for docking simulation.

2.2.6. Ligand Preparation. The 2D structures of the compounds were built and then converted into the $3 \mathrm{D}$. The $3 \mathrm{D}$ structures were then energetically minimized up to the rms gradient of 0.01 using MMFF.

2.2.7. Identification of Cavities. By using cavity determination option of software, cavities of enzyme were determined. The cavities in the receptor were mapped to assign an appropriate active site. The basic feature used to map the cavities were the surface mapping of the receptor and identifying the geometric voids as well as scaling the void for its hydrophobic characteristics. Hence, all the cavities that are present in receptor are identified and ranked based on their size and hydrophobic surface area. Considering the dimensions and hydrophobic surface area, cavity- 1 with 
TABle 2: Tyrosinase inhibition activity of title compounds.

\begin{tabular}{|c|c|c|c|c|c|}
\hline \multirow{2}{*}{ Compound } & \multicolumn{5}{|c|}{ Percentage inhibition of enzyme tyrosinase } \\
\hline & $10 \mu \mathrm{g}$ & $20 \mu \mathrm{g}$ & $40 \mu \mathrm{g}$ & $80 \mu \mathrm{g}$ & $100 \mu \mathrm{g}$ \\
\hline Kojicacid & 7.86 & 15.22 & 28.95 & 42.52 & 54.01 \\
\hline $4 a$ & 2.71 & 4.02 & 5.38 & 7.21 & 15.21 \\
\hline $4 b$ & 2.61 & 3.62 & 7.51 & 10.12 & 8.91 \\
\hline $4 c$ & 4.38 & 17.89 & 25.39 & 35.41 & 40.51 \\
\hline $4 d$ & 4.91 & 15.67 & 23.77 & 32.18 & 36.13 \\
\hline $4 e$ & 5.03 & 12.38 & 20.61 & 28.41 & 38.11 \\
\hline $4 \mathrm{f}$ & 2.71 & 5.54 & 7.81 & 10.02 & 12.02 \\
\hline $4 g$ & 2.57 & 6.91 & 8.27 & 12.14 & 17.61 \\
\hline $4 h$ & 6.57 & 18.37 & 28.16 & 34.59 & 39.71 \\
\hline $4 i$ & 4.71 & 10.62 & 18.71 & 28.72 & 35.78 \\
\hline $4 j$ & 3.68 & 15.12 & 21.91 & 27.83 & 33.81 \\
\hline $4 \mathrm{k}$ & 2.27 & 6.92 & 10.61 & 12.18 & 18.62 \\
\hline 41 & 3.11 & 12.62 & 20.68 & 25.51 & 32.56 \\
\hline $4 m$ & 3.98 & 15.68 & 28.19 & 37.76 & 41.14 \\
\hline $4 n$ & 2.51 & 10.16 & 12.72 & 16.22 & 22.16 \\
\hline 40 & 2.97 & 8.91 & 15.74 & 22.02 & 28.34 \\
\hline $4 p$ & 4.18 & 15.71 & 17.81 & 22.61 & 31.57 \\
\hline $4 q$ & 3.38 & 8.62 & 20.63 & 26.51 & 34.62 \\
\hline $4 r$ & 4.61 & 15.76 & 28.63 & 36.44 & 47.92 \\
\hline $4 s$ & 4.01 & 11.88 & 20.81 & 26.61 & 31.54 \\
\hline $4 t$ & 4.62 & 10.81 & 15.42 & 20.98 & 33.02 \\
\hline
\end{tabular}

TABLE 3: Selected QSAR model.

\begin{tabular}{|c|c|c|c|c|c|}
\hline $\begin{array}{l}\text { Model } \\
\text { number }\end{array}$ & Equation & $n$ & $r^{2}$ & $q^{2}$ & $F$ test \\
\hline 1. & $\begin{array}{c}\log \% I_{100 \mu \mathrm{g}}=-0.0005- \\
147.0670( \pm 10.4994) \\
\text { S_793 }+0.0183 \\
( \pm 0.0028) \text { S_757 }+ \\
0.0339( \pm 0.0074) \text { E_550 }\end{array}$ & 16 & 0.8920 & 0.8187 & 33.0329 \\
\hline
\end{tabular}

volume $219.531250 \AA^{3}$ and surface area $340.284790 \AA^{2}$ was found to be the best void as an active site.

2.2.8. Scoring Function. Distinction of good or bad docked conformation is based on scoring or fitness function. MDS uses fitness functions on only electrostatic and both steric and electrostatic interactions between receptor ligand as well as dock score scoring function. The dock score compute binding affinity of a given protein-ligand complex with known 3D structure.

\section{Results and Discussion}

3.1. Tyrosinase Inhibition Activity. The percentage inhibition of enzyme tyrosinase by compounds $\mathbf{4 a - 4 t}$ is estimated at concentrations of $10,20,40,80$, and $100 \mu \mathrm{g}$ and observed to be dose dependent. The compounds $4 \mathbf{c}, \mathbf{4 h}, \mathbf{4 m}$, and $4 \mathbf{r}$

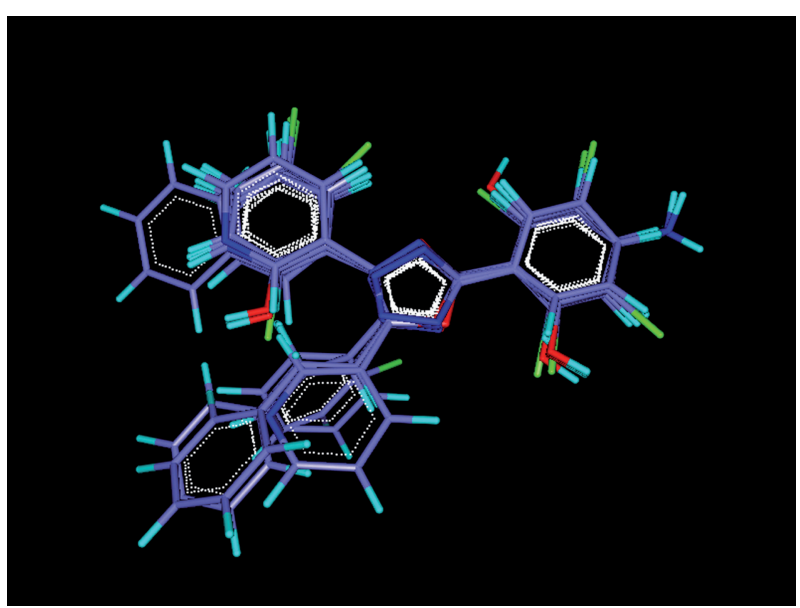

Figure 3: Aligned molecule (stick model).

shows maximum where compounds $\mathbf{4 b}, \mathbf{4 f}, \mathbf{4 g}$, and $\mathbf{4 k}$ shows minimum inhibition of enzyme tyrosinase from the series.

3.2. 3D QSAR. The model 1 describes the optimum structural feature for the tyrosinase inhibition activity as shown in Table 3. The training set of 16 molecules and test set of 4 molecules were used as described earlier. S_793, S_757, E_550 are the steric and electrostatic field energy of interactions between probe $\left(\mathrm{CH}_{3}\right)$ and compounds at their 
TABLE 4: Selected descriptors, actual and predicted activity of tyrosinase inhibitors.

\begin{tabular}{|c|c|c|c|c|c|c|}
\hline \multirow{2}{*}{ Compound } & \multicolumn{3}{|c|}{ Descriptors } & \multicolumn{3}{|c|}{ Activity } \\
\hline & S_793 & S_757 & E_550 & Actual & Predicted & Residue \\
\hline$* * 4 a$ & -0.00631 & 17.92055 & 2.079088 & 1.182129 & 1.325233 & -0.1431 \\
\hline $4 b$ & -0.00557 & 10.99283 & -0.7936 & 0.949878 & 0.992882 & -0.043 \\
\hline $4 c$ & -0.00743 & 20.20807 & 2.151223 & 1.607562 & 1.533583 & 0.073979 \\
\hline $4 d$ & -0.00743 & 20.20807 & 2.151223 & 1.557868 & 1.533583 & 0.024285 \\
\hline $4 e$ & -0.00651 & 30 & 1.927336 & 1.581039 & 1.569836 & 0.011203 \\
\hline $4 f$ & -0.00574 & 19.12609 & -1.80536 & 1.079904 & 1.131727 & -0.05182 \\
\hline $4 \mathrm{~g}$ & -0.00629 & 18.09468 & 3.132391 & 1.245759 & 1.361143 & -0.11538 \\
\hline$* * 4 h$ & -0.00574 & 10.46793 & -0.80766 & 1.5989 & 1.007527 & 0.591373 \\
\hline${ }^{* *} 4 \mathbf{i}$ & -0.00744 & 19.83572 & 4.267113 & 1.55364 & 1.600056 & -0.04642 \\
\hline $4 j$ & -0.00744 & 19.83572 & 4.267113 & 1.529045 & 1.600056 & -0.07101 \\
\hline $4 k$ & -0.00654 & 30 & -5.24257 & 1.26998 & 1.331729 & -0.06175 \\
\hline 41 & -0.0076 & 30 & -5.36661 & 1.512684 & 1.483861 & 0.028823 \\
\hline $4 \mathrm{~m}$ & -0.00607 & 30 & 2.570345 & 1.614264 & 1.527344 & 0.08692 \\
\hline $4 n$ & -0.0069 & 6.383675 & 3.156899 & 1.34557 & 1.23779 & 0.10778 \\
\hline${ }^{* *} 40$ & -0.00772 & 17.78855 & 1.660719 & 1.4524 & 1.516313 & -0.06391 \\
\hline $4 p$ & -0.00772 & 17.78855 & 1.660719 & 1.499275 & 1.516313 & -0.01704 \\
\hline $4 q$ & -0.00673 & 30 & 1.170805 & 1.539327 & 1.577306 & -0.03798 \\
\hline $4 r$ & -0.00787 & 30 & 1.006801 & 1.680517 & 1.73882 & -0.0583 \\
\hline $4 s$ & -0.00637 & 30 & -2.43434 & 1.852554 & 1.805904 & 0.097768 \\
\hline $4 t$ & -0.00694 & 30 & -2.22493 & 1.782629 & 1.694316 & 0.025586 \\
\hline
\end{tabular}

${ }^{* *}$ Test set compounds.

TABLE 5: Correlation matrix of $\log \% I_{100 \mu \mathrm{g}}$ with descriptor for model 1.

\begin{tabular}{|c|c|c|c|c|}
\hline & $\log \% I_{100 \mu \mathrm{g}}$ & E_550 & S_757 & S_793 \\
\hline $\log \% I_{100 \mu \mathrm{g}}$ & 1.000000 & & & \\
\hline E_550 & 0.256360 & 1.000000 & & \\
\hline S_757 & 0.403622 & -0.320018 & 1.000000 & \\
\hline S_793 & -0.46893 & -0.372145 & -0.066491 & 1.000000 \\
\hline
\end{tabular}

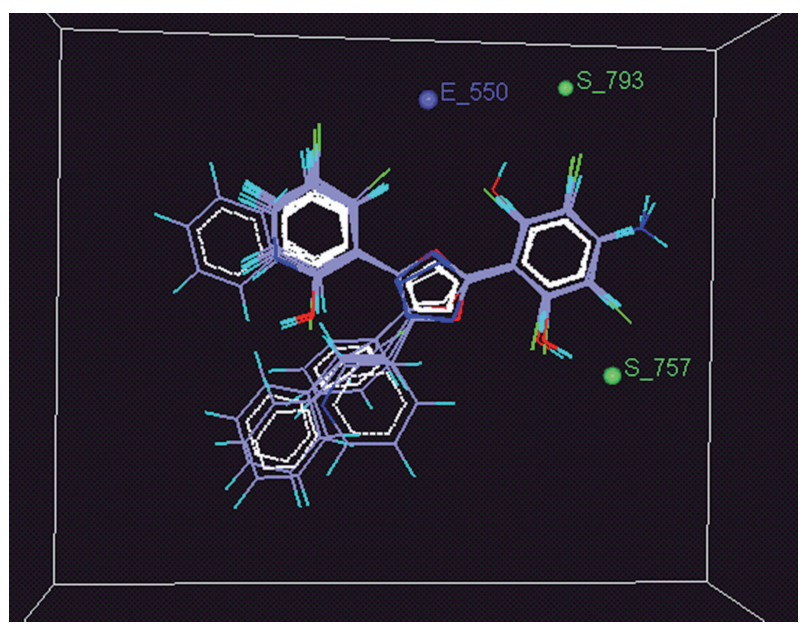

FIGURE 4: 3D QSAR model spatial grid points. corresponding spatial grid points of 793, 757, and 550 as shown in Figure 4. Low residual value observed in case of training as well as test set (Table 4 and Figure 5) confirms reliability of the QSAR model 1 . The selected descriptors have good correlation with biological activity and a low intercorrelation among them depicted in Table 5. As per model 1, steric descriptor S_793 with negative coefficients represent less bulky substituent is favourable; S_757 with positive coefficients represent more bulky substituent is favourable at 2,5-disubstituted oxadiazole nucleus while electrostatic field descriptor E_550 with positive coefficient indicate electropositive groups is favourable for activity. Compound $4 \mathbf{r}$ in the dataset bearing less bulky and electropositive chloro(hyroxy)phenyl rings on oxadiazole nucleus is most active, whereas less electropositive substituted oxadiazole nucleus in compound $\mathbf{4 b}$ is least active which indicates that developed 3D QSAR model satisfies model requirements. 
TABLE 6: Grid docking score of title compounds.

\begin{tabular}{lcc}
\hline Sr. no. & Compound & $\begin{array}{c}\text { Docking score } \\
(\text { Kcal/mol })\end{array}$ \\
\hline 1 & $\mathbf{4 a}$ & -4.8032 \\
2 & $\mathbf{4 b}$ & -4.9936 \\
3 & $\mathbf{4 c}$ & -5.2345 \\
4 & $\mathbf{4 d}$ & -5.3241 \\
5 & $\mathbf{4 e}$ & -5.1800 \\
6 & $\mathbf{4 f}$ & -4.7232 \\
7 & $\mathbf{4 g}$ & -4.8539 \\
8 & $\mathbf{4 h}$ & -5.2711 \\
9 & $\mathbf{4 i}$ & -5.3660 \\
10 & $\mathbf{4 j}$ & -5.2453 \\
11 & $\mathbf{4 k}$ & -5.3106 \\
12 & $\mathbf{4 l}$ & -5.4441 \\
13 & $\mathbf{4 m}$ & -5.0124 \\
14 & $\mathbf{4 n}$ & -4.9321 \\
15 & $\mathbf{4 o}$ & -5.4969 \\
16 & $\mathbf{4 p}$ & -5.4867 \\
17 & $\mathbf{4 q}$ & -5.3207 \\
18 & $\mathbf{4 r}$ & -5.8169 \\
19 & $\mathbf{4 s}$ & -5.1214 \\
20 & $\mathbf{4 t}$ & -5.1318 \\
\hline & &
\end{tabular}

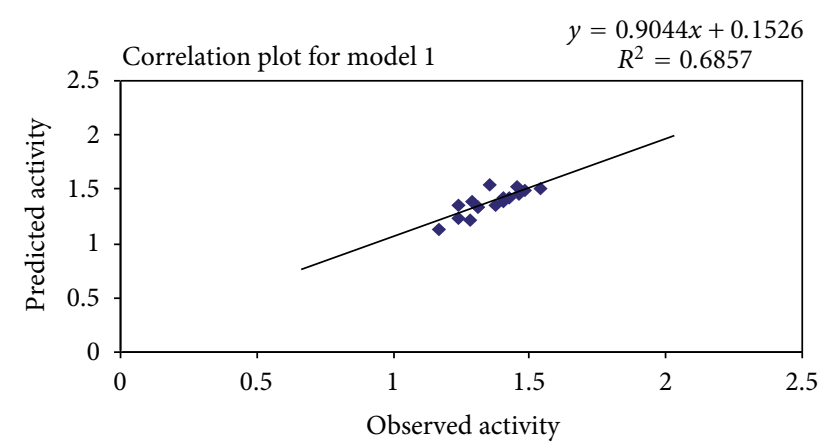

Figure 5: Plot of predicted against observed tyrosinase inhibition activity (model 1).

3.3. Docking. Docking studies of the title compounds with enzyme tyrosinase yielded docking score ranging from -5.8169 to -4.7232 (Table 6) indicating stable enzyme-substrate interactions. The compound $\mathbf{4 r}$ with best docking score $(-5.8169)$ has shown highest inhibition of enzyme tyrosinase in the dataset. The compounds interact with enzyme tyrosinase by binding with SER142, SER146, GLY145, and GLY198 amino acid residues as shown in Figure 6 . The tyrosinase inhibitory assay and molecular docking study reveals that 2,5-disubstituted-1,3,4-oxadiazoles inhibits enzyme tyrosinase may be because of its interaction with SER142, SER146, GLY145, and GLY198 amino acid residues.

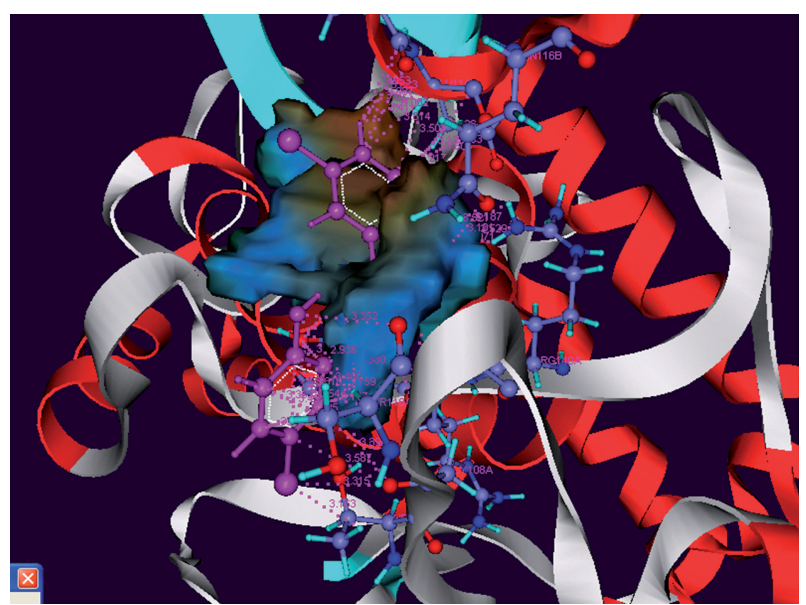

FIGURE 6: Interaction of compound 4r with mushroom tyrosinase.

\section{Conclusion}

It can be concluded from the whole study that electropositivity is crucial for the inhibition of enzyme tyrosinase by 2,5-disubstituted-1,3,4-oxadiazoles. It would be worthwhile to synthesize a novel 1,3,4-oxadiazole analogues with less bulky and more electropositivity group as a better enzyme tyrosinase inhibitors.

\section{References}

[1] Y. J. Kima and H. Uyamab, “Tyrosinase inhibitors from natural and synthetic sources: structure, inhibition mechanism and perspective for the future," Cellular and Molecular Life Sciences, vol. 62, no. 15, pp. 1707-1723, 2005.

[2] F. G. Cánovas, F. García-Carmona, J. V. Sánchez, J. L. IborraPastor, and J. A. Lozano-Teruel, "The role of $\mathrm{pH}$ in the melanin biosynthesis pathway," The Journal of Biological Chemistry, vol. 257, no. 15, pp. 8738-8744, 1982.

[3] J. N. Rodríguez-López, J. Tudela, R. Varón, and F. GarcíaCánovas, "Kinetic study on the effect of $\mathrm{pH}$ on the melanin biosynthesis pathway," Biochimica et Biophysica Acta, vol. 1076, no. 3, pp. 379-386, 1991.

[4] C. J. Cooksey, P. J. Garratt, E. J. Land et al., "Evidence of the indirect formation of the catecholic intermediate substrate responsible for the autoactivation kinetics of tyrosinase," The Journal of Biological Chemistry, vol. 272, no. 42, pp. 26226-26235, 1997.

[5] J. M. Pawelek and A. M. Korner, "The biosynthesis of mammalian melanin," American Scientist, vol. 70, no. 2, pp. 136-145, 1982.

[6] A. M. Mayer, "Polyphenol oxidases in plants-recent progress," Phytochemistry, vol. 26, no. 1, pp. 11-20, 1986.

[7] J. R. Whitaker, "Polyphenol oxidase," in Food Enzymes: Structure and Mechanism, D. W. S. Wong, Ed., vol. 271, Chapman and Hall, New York, NY, USA, 1995.

[8] M. Friedman, "Food browning and its prevention: an overview," Food Chemistry, vol. 44, no. 3, pp. 631-653, 1996.

[9] F. M. Barrett, "Wound-healing phenoloxidase in larval cuticle of Calpodes ethlius (Lepidoptera: Hesperiidae)," Canadian Journal of Zoology, vol. 62, no. 5, pp. 834-838, 1984. 
[10] M. Sugumaran, "Molecular mechanisms for cuticular sclerotization," Advances in Insect Physiology, vol. 21, pp. 179-231, 1988.

[11] K. Maeda and M. Fukuda, "In vitro effectiveness of several whitening cosmetic components in human melanocytes," Journal of the Society of Cosmetic Chemists, vol. 42, no. 6, pp. 361-368, 1991.

[12] T. S. Chang, "An updated review of tyrosinase inhibitors," International Journal of Molecular Sciences, vol. 10, no. 6, pp. 2440-2475, 2009.

[13] M. T. H. Khan, "Molecular design of tyrosinase inhibitors: a critical review of promising novel inhibitors from synthetic origins," Pure and Applied Chemistry, vol. 79, no. 12, pp. 2277-2295, 2007.

[14] F. Artes, M. Castaner, and M. I. Gil, "Review: enzymatic browning in minimally processed fruit and vegetables," Food Science and Technology International, vol. 4, no. 6, pp. 377-389, 1998.

[15] R. L. Sawant and P. D. Lanke, "Microwave assisted synthesis and 3D QSAR analysis of analgesic oxadiazoles," International Journal of Drug Design and Discovery, vol. 1, no. 4, pp. 336-344, 2010.

[16] S. Tadtong, A. Viriyaroj, S. Vorarat, S. Nimkulrat, and S. Suksamrarn, "Antityrosinase and antibacterial activities of mangosteen pericarp extract," Journal of Health Research, vol. 23, no. 2, pp. 99-102, 2009.

[17] T. A. Halgren, "Merck molecular force field. III. Molecular geometries and vibrational frequencies for MMFF94," Journal of Computational Chemistry, vol. 17, no. 5-6, pp. 553-586, 1996.

[18] S. Ajmani, K. Jadhav, and S. A. Kulkarni, "Three-dimensional QSAR using the k-nearest neighbor method and its interpretation," Journal of Chemical Information and Modeling, vol. 46, no. 1, pp. 24-31, 2006.

[19] M. S. Bhatia, K. B. Ingale, P. B. Choudhari, R. L. Sawant, and C. R. Patil, "Two- and three-dimensional quantitative structureactivity relationships studies on a series of diuretics," Latin American Journal of Pharmacy, vol. 28, no. 6, pp. 927-931, 2009. 

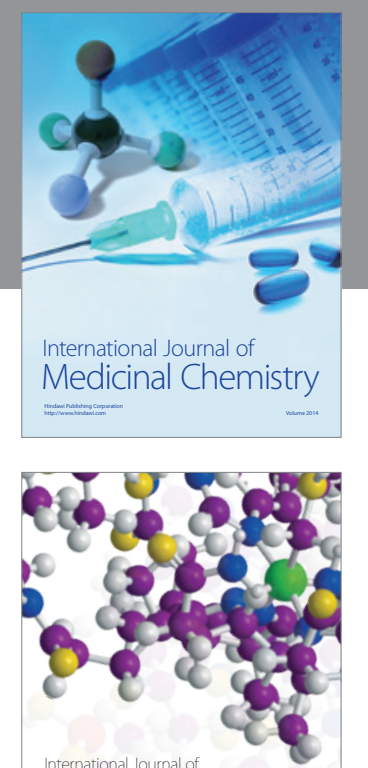

\section{Carbohydrate} Chemistry

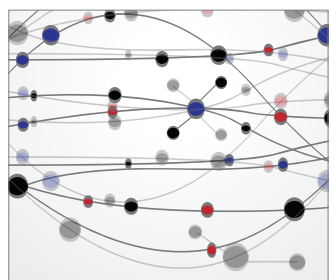

The Scientific World Journal
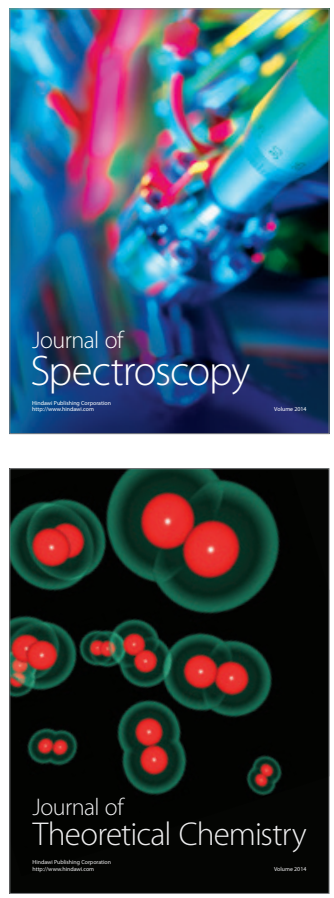
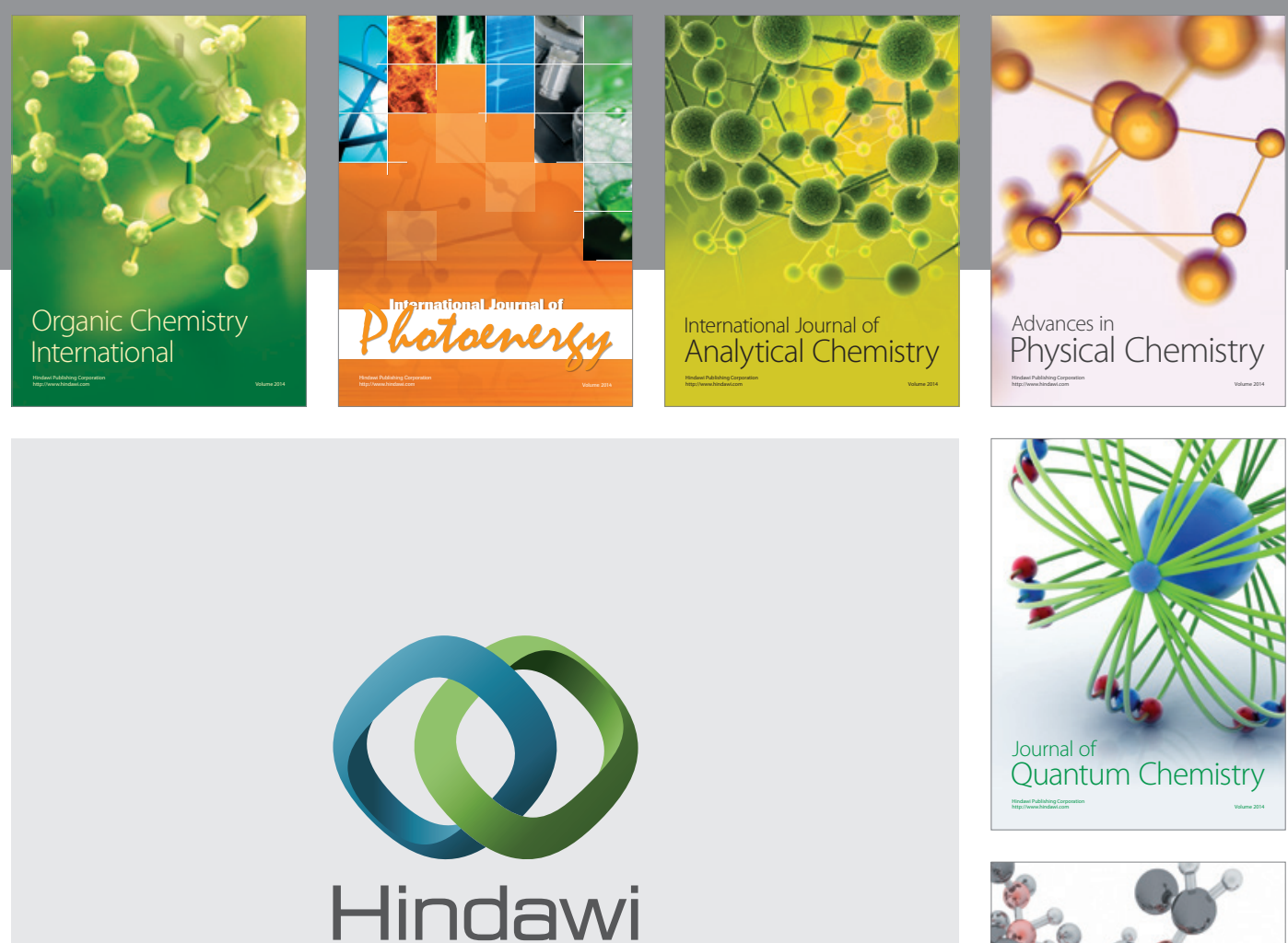

Submit your manuscripts at

http://www.hindawi.com

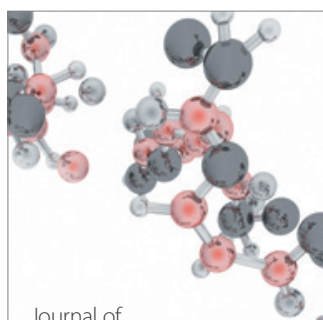

Analytical Methods

in Chemistry

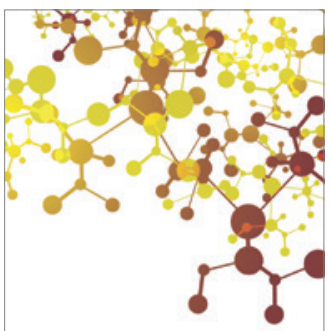

Journal of

Applied Chemistry

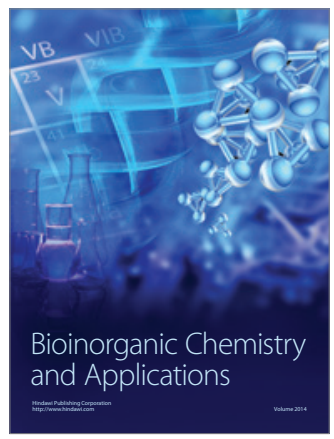

Inorganic Chemistry
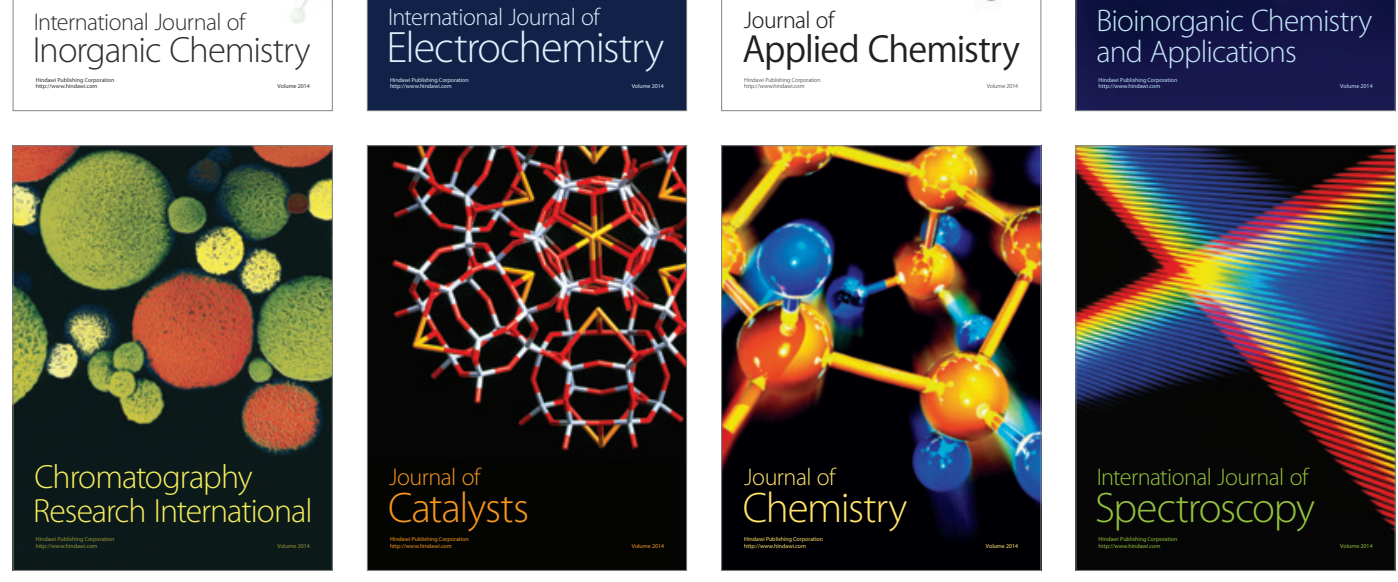